DOI: 10.14526/2070-4798-2020-15-2-33-40

\title{
Practical aspects of mesocycle organization of training among cadets, who go in for kettlebell lifting, taking into account the typology of their bioenergetics
}

\author{
Ilyas N. Ibragimov', Zinaida M. Kuznetsova ${ }^{2 *}$ \\ ${ }^{1}$ A.I. Proshlyakov Higher Military-Engineering College, Tyumen, Russia \\ "Naberezhnye Chelny branch of Management University "TISBI" \\ Naberezhnye Chelny, Russia \\ ORCID: oooo-ooo3-2158-5872, i-i-n@inbox.ru \\ ORCID: oooo-ooo2-5558-474X,kzm_diss@mail.ru*
}

\begin{abstract}
In modern world kettlebell lifting is used as the means of athletes power abilities development in different kinds of motor activity. However, power oriented kinds of sport nowadays demand the ways of power training individualization in terms of athletes different potential motor abilities. The article considers practical aspects of using the typology of bioenergetics in cadets, who go in for kettlebell lifting. Kettlebell lifting means are mainly directed toward power oriented abilities and special power endurance development. Taking into consideration the source of muscle activity energy supply in cadets, who go in for kettlebell lifting, helps to reconsider the use of different training means during the process of their sports training. This factor can be the base of competitive activity effectiveness increase. Research methods. Cadets (40 students from Tyumen Higher MilitaryEngineering College (military Institute in Tyumen, Russia)), who go in for kettlebell lifting, took part in the research. Material of the work was studying cadets' different biotypes and on this base modeling different mesocycles of sports training organization. Results. Mesocycles of training organization in cadets, who go in for kettlebell lifting, helps to provide effective summary training effect. It can be expressed by physical, functional readiness indices and the effectiveness of competitive activity improvement. Revealing cadets' biotypes depending on the level of qualification showed that there are all profiles of bioenergetics among them. We created model program with different variants of combining the level of physical load, especially in such mesocycles, as involving, basic, controlpreparatory, pre-competitive, competitive and rehabilitation, taking into account the direction of the included microcycles of training. Realization of different variants of physical load combination in micro and mesocycles of sport training, taking into account cadets' biotypes helps to increase physical working capacity and functional state recovery after competitive activity. Conclusion. Creating model variants of load direction combination not only in microcycles, but also in mesocycles of training helps to realize the correction of the program in macrocycle of training. The longer is the training process of cadets, the longer should be the exit of a tense state owing to timely physical working capacity rehabilitation not only during the rehabilitation period, but also when it is necessary. It is important to plan the training lessons for cadets, taking into account the typology of bioenergetics. Such an approach helps to control adaptive processes of an organism at different stages of their training.

Keywords: cadets, planning, mesocycles, microcycles, sports training, biotypes.
\end{abstract}

For citation: Ilyas N. Ibragimov, Zinaida M. Kuznetsova* Practical aspects of mesocycle organization of training among cadets, who go in for kettlebell lifting, taking into account the typology of their bioenergetics. Russian Journal of Physical Education and Sport. 2020; 15(2): 28-33. DOI: 10.14526/2070-4798-2020-152-33-40

\section{INTRODUCTION}

Kettlebell lifting nowadays is an alternative to power training in young men and pre-induction age youth and also in military men of all kinds of departments. This kind of sport is especially cultivated at military higher educational establishments. Cadets train regularly for their physical mastery development and actively take part in kettlebell lifting competitive activity. If we compare the quality of training, competitive tension and competitions effectiveness in kettlebell lifting, we can mention that there is considerable difference. It affected the tempo of this kind of sport development in the country and in the world [10,11]. Broadening the calendar of competitions and constant rules development demand the program of training reconsideration, taking into account the factors of sports training individualization. It was 
stated that kettlebell lifting development as a team kind of sport provided its popularity improvement among military higher educational establishments and audience appeal of this kind of sport increase. In this connection we should change the attitude to planning sports training. Nowadays it is necessary to create such methodology of training. It would provide not only the effectiveness of competitive activities in terms of equal conditions of athletes training but also strengthen the level of their physical health, sports longevity. Power oriented exercises demand the training process individualization in terms of their fulfillment specificity. It is also necessary to take into account not similar level of athletes' adaptive reaction to physical loads [7].

The main aim of power orientation physical exercises, used in sport, is apparatus movement from one position to another. This aim is achieved by different ways taking into account the kind of sport and the rules of competitions. For the kettle ball transfer "Burst" and "Push" movements are used together with rhythmic respiration. Kettle ball lifting combines dynamic and statistical positions. The main contribution into kettle ball movement is the work of the whole body of an athlete. Success in competitive activity of weightlifters directly depends on the degree of readiness. It includes interaction between different sides of training. During competitive activity of weightlifters different sides of sports training are combined into a complex of interactions and are demonstrated as sports result of performances.

Scientific-methodical sources analysis concerning the questions of sports training in power oriented kinds of sport, showed that physical readiness is conditioned by functional and adaptive abilities of an organism to physical loads and specific physical qualities demonstration. In this connection it is urgent to create and practically test the programs of training in kettlebell lifting, taking into account different mechanisms of muscle activity energy supply. Many authors consider the necessity to study functional state depending on typology of blood circulation and bioenergetics demonstration as the base for adaptive processes effectiveness increase $[1,3,4,5,6,7,11,12,13]$.

V.Yu. Pavlov (2012) underlines the necessity to create and use model characteristics as the base for the training process control in athletes $[8,9,10]$.

M.V. Nikityuk (2014) underlines that for high results achievement in sports activity among Greco-Roman wrestlers with different bioenergetics profile and individual source of muscle activity energy supply it is necessary to prevent adaptation breakdown. The author underlines, that pre-competitive motor regimen choice is mainly conditioned taking into account the advantages and disadvantages of wrestlers' bioenergetics profiles. Types revelation of wrestlers we realized according to three blocks of indices: general and special physical readiness, physical working capacity, functional state and reserve abilities of wrestlers' organism [7, p.97-103].

V.A. Salnikov (2017) also mentioned the necessity to take into account individual differences of weightlifters as the base for their training optimization.

Competitive activity analysis among highly-qualified weightlifters showed that their success is conditioned by aerobic productivity. It defines physical working capacity and organism bioenergetics systems abilities increase in different conditions. It is known that any muscle activity is realized with the help of three sources of muscle activity supply: aerobic, anaerobic and mixed. Each sourcehasits power, capacity, efficiency. Theydepend on an integral characteristic of their demonstration. Power and capacity of athletes' organism energy source can be trained and developed depending on orientation of the training influences. All mentioned above shows that working capacity of cadets, who go in for kettlebell lifting, is determined by the structure of energetic metabolism with power, capacity and efficiency of energetic source of muscle activity demonstration. Physiological base of the muscle activity energy supply source is characterized by aerobic productivity, anaerobic metabolism, power, capacity and efficiency of systems demonstration depending on specific conditions of the training process.

The aim of this research work was to plan the mesocycle of training cadets, who go in for kettlebell lifting, taking into account the typology of their bioenergetics.

It is known that training in kettlebell lifting 
in terms of a long-term training has multipurpose orientation. But it is important to have a rational and optimal combination of the training means and the training loads differentiation, taking into account the typology and individual peculiarities of weightlifters. This work was a preparatory research work for the planned pedagogical experiment substantiation. However, the results were interesting, as it was revealed that more successful among weightlifters can become the representatives of all kinds of bioenergetics typology, but in the training process means variants individualization and selection is important, taking into account the profile of bioenergetics. Below we show the example of planning the mesocycle of general preparatory stage of training cadets, who go in for kettlebell lifting.

\section{MATERIALS AND METHODS}

Cadets (40 people) from Tyumen Higher Military-Engineering Command College (military
Institute) in Tyumen (Russia), whogo in for kettlebell lifting, took part in the research. We defined the bioenergetics types of cadets by means of expressdiagnostics method "D\&K-TEST". The research material of this work is presented by the results of the carried out research works and observations over the training process of cadets. They go in for kettlebell lifting during the whole period of studying at a higher educational establishment.

\section{RESULTS AND DISCUSSION}

During the first stage of the research we held the test and estimated the level of an organism functional state in athletes-weightlifters through bioenergetics profile study with the help of program methodology "D\&K-TEST" [2]. This research was held as a testing one before the main pedagogical experiment. Picture 1 presents the received results of cadets distribution, taking into account their biotypes.

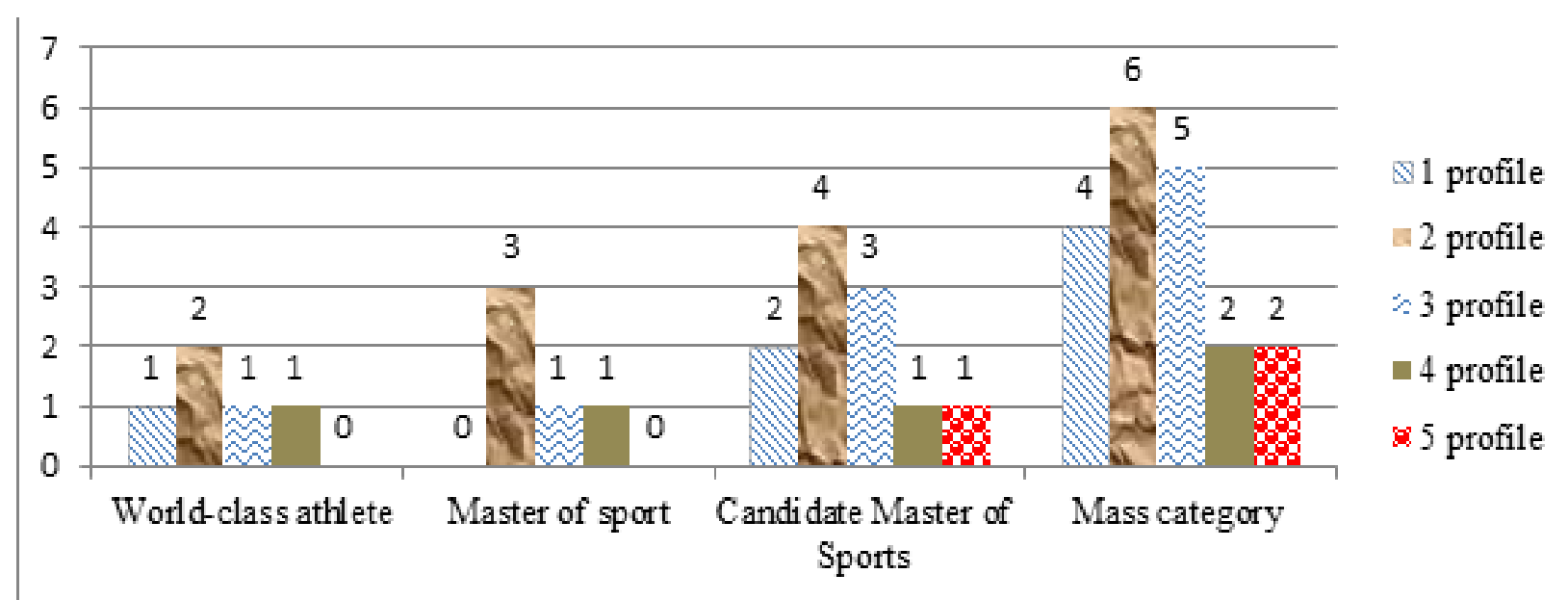

Fig. 1. Distribution of cadets, who go in for kettlebell lifting, according to biotypes (quantity)

Notes: WCA - World-class athlete; MS - master of sport; CMS - candidate master of sport; MC - mass categories

Cadets' typology revelation showed that among them there are all five types of bioenergetics profiles. Among WCA $(n=5)$ we revealed all profiles of bioenergetics: the $1^{\text {st }}, 3^{\text {rd }}$ and the $4^{\text {th }}$ profiles -1 cadet each; the $2^{\text {nd }}$ profile -2 cadets. Among MS cadets $(n=5)$ we revealed three profiles of bioenergetics: the $2^{\text {nd }}$ profile -3 cadets; the $3^{\text {rd }}$ and the $4^{\text {th }}$ profiles1 cadet each. Among CMS cadets $(n=11)$ we revealed all profiles: the $1^{\text {st }}$ profile- 2 cadets; the $2^{\text {nd }}$ profile -4 cadets; the $3^{\text {rd }}$ profile -3 cadets; the $4^{\text {th }}$ and the $5^{\text {th }}$ profile -1 cadet each. Among MC cadets $(n=19)$ we revealed all profiles: the $1^{\text {st }}$ profile -4 cadets; the $2^{\text {nd }}$ profile -6 cadets; the $3^{\text {rd }}$ profile -5 cadets; the $4^{\text {th }}$ and the $5^{\text {th }}$ profiles -2 cadets each.

For creating mesocycles of training cadets, who go in for kettlebell lifting, we took into account the advantages and disadvantages of bioenergetics profiles. The base for the methodology of training mesocycles creation was the concept of cumulative training effect achievement. It can be demonstrated in high level of physical, functional readiness formation and other components of competitive potential. We revealed adaptive potential of cadets taking into account the variants of muscle activity 
energy supply source. It is revealed during different intensity loads. Cumulative effect of training mesocycle is seen in adaptive reactions of an organism. It is quicker demonstrated in the work of higher nervous system and then in other systems of an organism. At the end of each microcycle in one mesocycle we reveal adaptive potential of organism to increasing physical loads in cadets, who go in for kettlebell lifting. An important component of mesocycles effectiveness is control over supporting the tempo of physical, functional and other readiness indices increase. Taking into account the tempo of increase demands training microcycles content renewal each 3-4 weeks, taking into account individual indices of cadets' functional state. It is known that each mesocycle of training can include several microcycles of different type. It helps to control the volume and intensity of the training loads and when it is necessary quickly correct them till the necessary training effect achievement.

Our example shows the variants of mesocycles: involving, basic, training, controlling, pre-competitive, competitive and rehabilitation in combination with multidirectional microcycles. After each three-week microcycle we include rehabilitation microcycle and especially after each physical and functional readiness rise in order to prevent overtiredness.

Table 1 presents the direction and combination of multidirectional variants of load in different microcycles in different types of training mesocycles realization in cadets, who go in for kettlebell lifting.

Table 1 - Variants of different level physical load combination in weekly microcycles taking into account the direction of a mesocycle in training cadets, who go in for kettlebell lifting.

\begin{tabular}{|c|c|c|c|c|}
\hline \multirow{2}{*}{$\begin{array}{l}\text { Types } \\
\text { mesocycles }\end{array}$} & \multicolumn{4}{|c|}{$\begin{array}{c}\text { Variants of microcycles and the level of the load taking into account the typology of } \\
\text { cadets' bioenergetics }\end{array}$} \\
\hline & 1 & 2 & 3 & 4 \\
\hline Involving & $\begin{array}{c}\text { I-1 (moderate } \\
\text { with the transfer } \\
\text { to the average } \\
\text { load) }\end{array}$ & I-2 (the average load) & $\begin{array}{c}\text { B-1 (the average } \\
\text { load with transfer } \\
\text { to considerable } \\
\text { load) }\end{array}$ & $\begin{array}{c}\text { I-1 (the } \\
\text { average load } \\
\text { with transfer } \\
\text { to small load) }\end{array}$ \\
\hline Basic & $\begin{array}{l}\text { B-1 (great load } \\
\text { with transfer } \\
\text { to considerable } \\
\text { load) } \\
\end{array}$ & $\begin{array}{l}\text { B-2 (above the average } \\
\text { load with transfer to } \\
\text { considerable load) }\end{array}$ & $\begin{array}{l}\text { B-3 (considerable } \\
\text { load with transfer } \\
\text { to great load) }\end{array}$ & $\begin{array}{l}\text { I-2 (the } \\
\text { average load } \\
\text { with transfer } \\
\text { to small load) }\end{array}$ \\
\hline $\begin{array}{l}\text { Control - } \\
\text { preparatory }\end{array}$ & T-1 (great load) & $\begin{array}{l}\text { T-2 modeled for } \\
\text { competitive activity } \\
\text { (great load) }\end{array}$ & $\begin{array}{l}\mathrm{T}-3 \text { (close to } \\
\text { maximum load) }\end{array}$ & $\begin{array}{c}\text { I-3 (the } \\
\text { average load } \\
\text { with transfer } \\
\text { to small load) }\end{array}$ \\
\hline Pre-competitive & $\begin{array}{l}\text { B-1 (great load } \\
\text { with transfer } \\
\text { to considerable } \\
\text { load) } \\
\end{array}$ & $\begin{array}{l}\text { T-2 modeled for } \\
\text { competitive activity } \\
\text { (great load) }\end{array}$ & $\begin{array}{l}\text { T-3 modeled for } \\
\text { competitive activity } \\
\text { (great load) }\end{array}$ & $\begin{array}{l}\text { Leading } \\
\text { (small load) }\end{array}$ \\
\hline Competitive & $\begin{array}{l}\text { Leading (the } \\
\text { average load) }\end{array}$ & Leading (small load) & \multicolumn{2}{|c|}{$\begin{array}{l}\text { Competitive (load volume depends } \\
\text { on the level of competitions) }\end{array}$} \\
\hline Rehabilitation & \multicolumn{3}{|c|}{ Rehabilitation } & $\begin{array}{l}\text { Involving } \\
\text { (small load) }\end{array}$ \\
\hline
\end{tabular}

Multidirectional load combination in each microcycle depends on the type of mesocycle at the stage of weightlifters long-term training. It effect achievement. The first involving mesocycle of training combined from 3 to 4 microcycles: involving and basic training directions. It is important to finish is important to take into account the regimen of physical load overlaying for cumulative training each mesocycle with one rehabilitation microcycle depending on the solved problems of each stage of 
training.

Included into semiannual macrocycle basic mesocycle can be realized both during the first and the second semiannual macrocycle of training weightlifters. It is important to take into account the amount of each mesocycle repetitions. During great and considerable physical loads realization for cadets-weightlifters it is important to include the regimen of functional abilities rehabilitation.

Control-preparatory mesocycles can be repeated several times within a macrocycle of training and depending on the objective of training. At the same time, control helps to change the orientation of a microcycle in order to get athletes' physical and functional readiness increase. It is important to take into account how different sources of muscle activity energy supply are included into cadets work,.

Pre-competitive mesocycle is repeated several times necessary for competitions training. At the same time we use model training lessons, where cadets can realize their readiness till $95 \%$. Leading microcycle takes into account the level of functional abilities demonstration in cadets before the start.

In competitive microcycle leading to start is held with the average and small loads alternation in order to keep high level of readiness for start. At the same time the average and small supporting loads alternate and when it is the day of start it is possible to include light training with competitive effect depending on advantages and disadvantages of cadets' bioenergetics profile.

In our example we offer to realize rehabilitation variants of mesocycle, which includes three rehabilitation microcycles with gradual transfer to involving stage of mesocycle of training repetition.

The peculiarity of such an approach to different types of mesocycles realization is important as after several microcycles we can have tiredness accumulation and the necessity to have rehabilitation microcycle in mesocycle. Such an approach helps to control and preserve cadets' accumulated training level.

Typical trait of presented by us mesocycles is, first of all, the possibility to change the level of physical loads orientation in them. The duration of mesocycles also doesn't have strict borders. It is connected with the definite problems of training solution incadets, who go in for kettlebell lifting. It is also conditioned by time. It is necessary for cadets' organism adaptation to a new level of functional readiness depending on typology of their bioenergetics.

HR tanm increase till the maximum level in cadets can be different. For example, aerobic types of bioenergetics have better HR tanm indices in the increasing power loads. Taking into account their typology helps to control the duration of the achieving maximal HR tanm phase, the necessary level of power abilities and special endurance increase. It is also important not only to achieve the desired level of HR tanm, but also stabilize and preserve it till competitions. In this connection taking into account the advantages and disadvantages in demonstration of energy supply muscle activity sources in cadets helps to correct the program of training for a new level of adaptation achievement and further effectiveness of cadets' competitive activity increase.

\section{CONCLUSION}

Thus, we can come to the conclusion that it is possible to create the model of the load orientation combination variants not only in microcycles, but also mesocycles of training with further program of training correction. It is important to take into consideration strict correspondence and transfer of involvement, tense training and rehabilitation periods. We defined the following: the longer the period of training is the longer should be exit out of a tense state owing to working capacity rehabilitation.

It is important to take into account the volume of the load and its specialty in training knowledge content. IT is important to plan the training lessons for cadets taking into account the typology of bioenergetics as such an approach helps to control adaptive processes of an organism.

\section{REFERENCES}

1. Grankin N.A., Kuznetsova Z.M. Indices of functional state and reserve capacities of organism among cadets-weightlifters. Pedagogikopsihologicheskie I medico-biologicheskie problemy fizicheskoj kul'tury I sporta = Pedagogicopsychological and medico-biological problems of physical culture and sport. 2017; 12(3): 58-67. DOI: 
10.14526/O3_2017_232 [In Russ., In Engl.]

2. Dushanin S.A. Bioenergetics monitoring in sport: new principles of express-control over aerobic and anaerobic threshold. Osnovy upravleniya trenirovochnym processom: sbornik nauchnyh trudov [The basis of training process control: collection of scientific works. Kiev: KSIPC. 1982: 80-88 [In Russ.].

3. Kuznetsova

Z.M., Ryabchuk

A.V., Labeshchenkov O.V. Theoretical and practical aspects of engineering profile cadets' airborne training individualization. Pedagogikopsihologicheskie I medico-biologicheskie problemy fizicheskoj kul'tury I sporta = The Russian /journal of Physical Edcuation and Sport. 2018; 13(2): 198206. DOI: 10.14526/02_2018_326 [In Russ., In Engl.]

4. Kuznetsova Z., Kuznetsov A., Mutaeva I., Khalikov G., Zakharova A. Athletes preparation based on a complex assessment of functional state. In Proceedings of the $3^{\text {rd }}$ International Congress on Sport Sciences Research and Technology support. SCITEPRESS. 2015: 156-160.

5. Komarov O.Yu., Sivokhin I.P., Fedorov A.I., Anrushchishin I.F. Mechanisms of energy supply and biochemical adaptation to competitive exercises in kettlebell lifting. Voprosy funkcional'noj podgotovki $v$ sporte vysshih dostizhenij [Questions of functional training in high achievements sport]. 2015; 3(1): 104-111 [In ].

6. Mutaeva I.Sh., Morozov A.I., Gizatullina Ch.A. Training athletes, who specialize in sprint, taking into account types of blood circulation and bioenergetics. Kontsept: nauchno-metodicheskij elektronnyj zhurnal. 2015; 13: 3741-3745 [In Russ.].

7. Nikityuk M.V. Theoretical substantiation of the methodology of training Greco-Roman wrestlers taking into account their bioenergetics profile. Pedagogiko-psihologicheskie I medicobiologicheskie problemy fizicheskoj kul'tury I sporta = Pedagogico-psychological and medico-b iological problems of physical culture and sport. 2014; 4(33): 97-103. URL: https://cyberleninka.ru/ article/n/teoreticheskoe-obosnovanie-metodikipodgotovki-bortsov-greko-rimskogo-stilya-suchetom-ih-bioenergeticheskogo-profilya/viewer [In Russ., In Engl.]

8. Pavlov V.Yu. Model characteristics as the base for controlling educational-training process among 13-15 year-old athletes-weightlifters. Vestnik TGU. 2012; 363: 188-192 [In Russ.].

9. Pavlov V.Yu. Model characteristics creation and use in the training process of young weightlifters. Vestnik TGU. 2012; 5(120): 147-153 [In Russ.].

10. Salnikov V.A. Individual differences as the base for sports activity optimization. Teoriya $I$ praktika fizicheskoj kul'tury = Theory and practice of physical culture. 2003; 7: 24-26 [In Russ., In Engl.].

11. Sandin S.M. Using kettlebell lifting means in the system of power oriented training of cadets at Volsk Military Institute of Material Supply. Uchenye zapiski universiteta imeni P.F. Lesgafta. 2017; 11(153): 219-223 [In Russ.].

12. Grassi B., Pogliaghi S., Rampichini S., Quaresima V., Ferrari M., Marconi C., et al. Muscle oxygenation and pulmonary gas exchange kinetics during cycling exercise on-transitions in humans. Journal of Applied Physiology. 2003; 95: 149-158.

13. Guennete J.A., Vogiatzis I., Zakunthinos S., Athanasopoulos D., Koskolou M., Golemati S., ..., Boushel B. Human respiratory muscle blood flow measured by near-infrared spectroscopy and indocyanine green. Journal of Applied Physiology. 2008; 104: 1202-1210.

\section{Submitted: 20.04.2020}

Ilyas N. Ibragimov - Senior Lecturer, A.I. Proshlyakov Higher Military-Engineering College, 625001, Russia, Tyumen, L. Tolstoj str.,House 1 (militarytown), e-mail: i-i-n@inbox.ru

Zinaida M. Kuznetsova - Doctor of Pedagogics, Professor, Naberezhnye Chelny branch of Management University "TISBI", 423806, Russia, Naberezhnye Chelny, Komsomolskaya nab., House 6, e-mail: kzm diss@mail.ru 